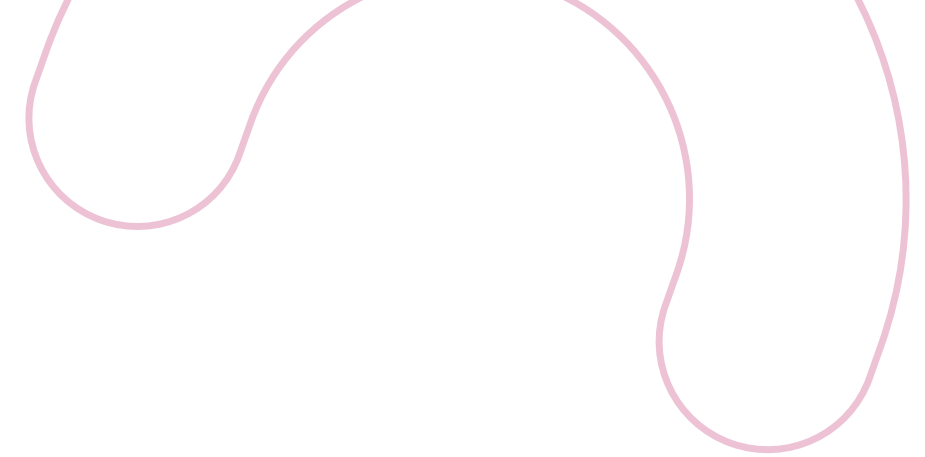

\title{
Os princípios do processo criativo no projeto de design de identidade gráfico-visual de marca
}

The principles of the creative process in graphic-visual brand identity design

Sarah Schmithausen Schmiegelow

Universidade Federal de Santa Catarina

sarahschmiegelow@gmail.com $\mathbf{x}$

Richard Perassi Luiz de Sousa

Universidade Federal de Santa Catarina

richard.perassi@uol.com.br $\mathbf{m}$

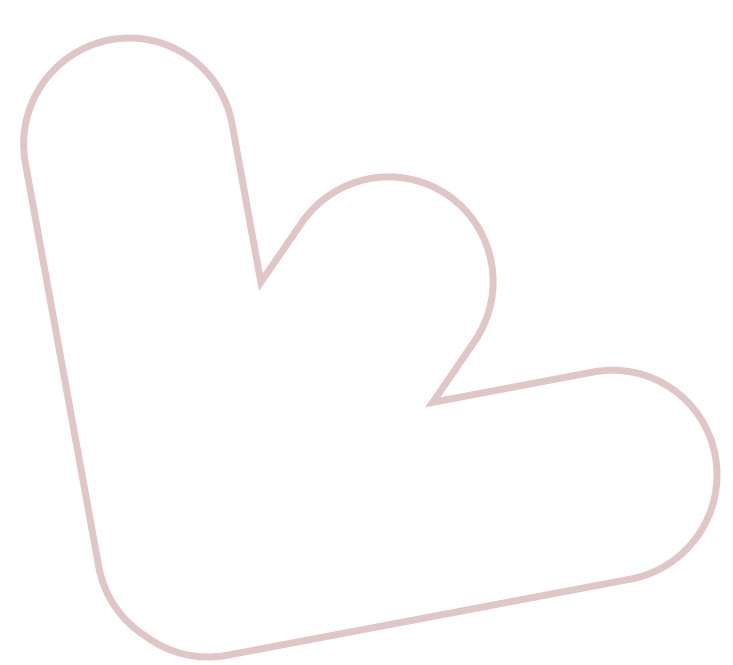

PROJËTICA

\section{COMO CITAR ESTE ARTIGO:}

SCHMIEGELOW, Sarah Schmithausen; SOUSA, Richard Perassi Luiz de. Os princípios do processo criativo no projeto de design de identidade gráfico-visual de marca. Projética, Londrina, v. 12, n. 1, p. 114-142, 2021.

DOI: 10.5433/2236-2207.2021v12n1p114

Submissão: 12-10-2018

Aceite: 08-01-2020 
RESUMO: Neste artigo é apresentada uma análise da etapa criativa de geração de alternativas em design de identidade gráfico-visual de marca. A análise é baseada em três princípios, retirados da literatura sobre técnicas de solução criativa de problemas: (1) abordagem intuitiva ou racional; (2) uso de estímulos relacionados ou não ao problema; e (3) associação livre ou forçada de elementos. Os resultados apontam o predomínio da intuição, estímulos relacionados ao problema e associações livres. Assim, a experiência e sensibilidade estética do designer são determinantes na gestão do percurso criativo e geração de ideias originais.

Palavras-chave: Criatividade. Identidade. Gráfico-visual de marca. Design gráfico. Geração de ideias.

ABSTRACT: In this paper, we present an analysis of the creative steps in designing ideas for graphic-visual brand identity. The analysis is based on three principles, drawn from creative problem-solving techniques found in the literature: (1) intuitive or rational approach; (2) use of related or unrelated stimuli; (3) free or forced elements association. Results indicate the predominance of intuition, the use of stimuli related to the problem and free associations. Thus, the experience and aesthetic sensibility of the designer are decisive in the management of the creative process and the generation of original ideas.

Keywords: Creativity. Graphic-visual brand Identity. Graphic design. Ideas generation.

\section{INTRODUÇÃO}

A atividade de Design atua por meio de projetos, quevisam à solução de determinados problemas (LÖBACH, 2001). A solução, ou produto do projeto, não resulta de uma livre configuração, mas é orientada por questões socioeconômicas, culturais, ergonômicas e ecológicas, entre outras (BÜRDEK, 2006). O que tradicionalmente 
caracteriza o campo de Design, e o diferencia da produção artesanal, é a aplicação de linguagem geométrica, que permite a interpretação lógica e produção em série dos produtos projetados (PERASSI, 2015).

Ao caracterizar Design, no entanto, não se pode deixar de lado a criatividade como componente do desenvolvimento projetual. Alencar (2005) explica que a criatividade está relacionada a processos de pensamento associados à imaginação, insight, invenção, inovação, intuição, inspiração, iluminação e originalidade. Como complementa Ostrower (2010), a criatividade se revela na capacidade humana de selecionar, relacionar e integrar dados do mundo externo e interno, alterando-os em busca de um sentido mais completo.

Em Design, a lógica, requerida para a reprodução de produtos idênticos em funcionalidade e aparência, contrasta com o pensamento livre, fantasioso e divergente necessário na etapa de geração de alternativas para a solução do problema. A aplicação da criatividade no projeto leva o designer a sair do lugar comum, da solução óbvia, resultando em produtos originais e inovadores, valores requeridos devido à competitividade atual do mercado.

Entre as áreas de atuação em Design, o desenvolvimento de identidade gráfico-visual é uma especialidade de Design Gráfico dedicada à criação dos elementos gráfico-visuais de marca, que incluem marca gráfica ou assinatura visual, cores e tipografias, entre outros. Utiliza-se o termo "identidade gráfico-visual" para indicar o domínio do Design Gráfico na identidade visual de marca, pois o termo "identidade visual" abrange a totalidade de expressões visuais que identificam a marca, incluindo também outros aspetos como produtos e arquitetura.

O objetivo dos elementos visuais, bem como de todos os elementos sonoros, olfativos, táteis e gustativos associados à marca, é expressar a identidade de marca, definida por Kapferer (2008) como os valores centrais, crenças e visão da marca. A identidade, junto ao posicionamento, define o modo como a marca irá se diferenciar das suas competidoras no mercado.

É evidente o papel da criatividade como modo de assegurar que os elementos gráfico-visuais de marca tenham visibilidade frente ao excesso de comunicação que os consumidores são expostos diariamente. A originalidade, a 
capacidade de diferenciação é uma questão de sobrevivência para as marcas, e isto inclui o modo como ela é representada visualmente.

Neste contexto, o presente artigo tem como objetivo apresentar uma análise dos princípios de criatividade utilizados nos projetos de identidade gráficovisual de marca. Aqui, entende-se por princípios os mecanismos que caracterizam, especialmente, a etapa de geração de ideias do processo criativo. Estes foram retirados de estudos que examinam teoricamente o funcionamento das diversas técnicas de resolução criativa de problemas disponíveis, como Brainstorming, Estimulação de Objeto, Análise de Campo de Força, entre outras.

Trata-se de uma pesquisa teórica, de abordagem predominantemente descritiva e de base qualitativa. Também contém uma etapa inicial de abordagem exploratória, na qual, por meio de procedimentos técnicos de pesquisa secundária, foi levantado o referencial teórico que fundamentou a discussão proposta. Em uma pesquisa descritiva, conforme Valentim (2005), são feitas observações, registros, correlações e descrições de fenômenos, mas não prevê interferência na realidade observada.

Assim, o fenômeno aqui descrito é a geração de alternativas da etapa criativa dos projetos de Design de identidade gráfico-visual de marca, que será descrita sob a perspectiva de princípios retirados de técnicas criativas. A estrutura do artigo é composta por uma revisão de literatura de criatividade, princípios de técnicas criativas e da etapa criativa de projetos de identidade gráfico-visual, seguida da discussão e finalizada com as considerações da pesquisa.

\section{REVISÃO DE LITERATURA}

\subsection{Criatividade}

Conforme Hennessey e Amabile (2010), a maior parte dos autores e pesquisadores concorda que a criatividade está relacionada ao desenvolvimento de um novo produto, ideia ou solução, que tenha valor tanto para o indivíduo quanto para a 
sociedade. Criatividade, portanto, envolve um processo, individual ou em equipe, que culmina em um resultado caracterizado pela novidade, ao menos do ponto de vista do indivíduo ou grupo gerador da ideia, e pelo valor ou utilidade (ALENCAR, 2005; KING; SCHILICKSUPP, 1999).

O conceito de criatividade está relacionado com o de inovação, mas trata-se de domínios distintos. A criatividade é o processo pelo qual as ideias são geradas, enquanto a inovação está voltada à aplicação, concretização das ideias (ALENCAR, 2005; KING; SCHILICKSUPP, 1999). Neste sentido, Alencar (2005) indica que a criatividade costuma ser usada no nível de indivíduos ou grupos, e a inovação no contexto organizacional.

A criatividade não é considerada um dom inato, mas uma capacidade natural do ser humano, que está ao alcance de qualquer indivíduo (ALENCAR, 2005; KING; SCHILICKSUPP, 1999; OSTROWER, 2010; VANZIN; ULBRICHT, 2010). Assim, os estudos da área incluem diversos aspectos que permeiam a expressão da criatividade. As diferentes abordagens costumam enfatizar um ou mais dos seguintes aspectos: processo, produto, pessoa ou personalidade, contexto, e mais recentemente, persuasão e potencial (KOZBELT; BEGHETTO; RUNCO, 2010).

Este estudo aborda, principalmente, a perspectiva do processo criativo. Esta abordagem busca compreender os mecanismos mentais envolvidos com o pensamento criativo, os estágios conscientes e inconscientes do processo, a diferença entre os processos movidos ao acaso dos processos controlados, entre outras questões (KOZBELT; BEGHETTO; RUNCO, 2010). Dentro desta abordagem, o recorte específico são as fases do processo criativo, em especial mecanismos associados à fase de geração de ideias.

Acerca das fases que estruturam o processo criativo, Rigolizzo e Amabile (2015) retomam as ideias de Amabile (1983), indicando quatro etapas: (1) identificação do problema ou oportunidade, (2) preparação, (3) geração de ideias, e (4) avaliação e implementação da ideia (Quadro 1). Durante a primeira etapa, o problema ou oportunidade é trabalhado com o objetivo de aumentar as chances de gerar soluções novas e aplicáveis. A segunda etapa do processo criativo, preparação, 
refere-se à aquisição de conhecimentos no domínio do problema. Trata-se da coleta de informações e recursos para a compreensão do que já foi usado ou não para solucionar o problema (RIGOLIZZO; AMABILE, 2015). Alencar (2005) destaca que a qualidade das informações obtidas acerca do problema influencia a geração de ideias originais e de valor.

Quadro 1 - Etapas do processo criativo método

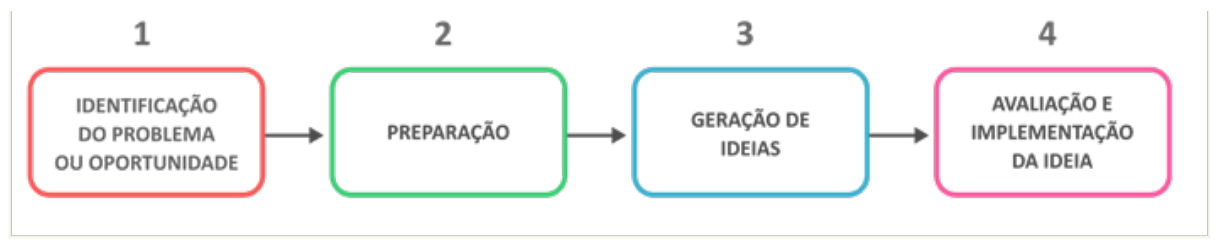

Fonte: Baseado em Amabile (1983) e Rigolizzo e Amabile (2015).

A terceira etapa, de geração de ideias, é quando as informações coletadas são relacionadas ao conhecimento já existente, com vistas a estabelecer novas conexões e criar novas soluções. A meta é produzir uma grande quantidade de ideias, bem como ideias de alta qualidade (RIGOLIZZO; AMABILE, 2015). Geralmente, incentiva-se a produção de grande quantidade de ideias, pois quanto mais ideias, maior a probabilidade de que sejam geradas ideias novas e interessantes (KING; SCHILICKSUPP, 1999). Em relação à novidade de uma ideia, Garfield et al. (2001) entendem como sua raridade ou singularidade, e completam que ideias mais óbvias são geradas com mais frequência do que ideias mais novas.

A etapa de geração de ideias depende de processos cognitivos flexíveis, que podem ser estimulados por técnicas que facilitam o pensamento criativo (RIGOLIZZO; AMABILE, 2015). Ward (2004), sob um ponto de vista cognitivo, explica que as ideias criativas surgem da aplicação de operações mentais básicas, e que a originalidade de uma ideia é determinada pelos processos empregados e o modo como o conhecimento já existente é acessado. 
A geração de ideias está associada ao pensamento divergente, que proporciona a produção de muitas e variadas ideias (RIGOLIZZO; AMABILE, 2015), bem como ideias originais e singulares (KING; SCHILICKSUPP, 1999). No entanto, Kozbelt, Beghetto e Runco (2010) alertam que o pensamento divergente pode resultar em ideias irrelevantes caso seja aplicado sem moderação. Da mesma forma, a mudança de perspectiva, considerada promovedora de insights originais, se torna inútil quando leva a soluções e ideias que não podem ser conectadas ao problema. Isto demonstra a importância da convergência na etapa seguinte.

A última etapa do processo criativo é composta por dois elementos: avaliação e implementação da ideia. Visto que nem todas as ideias produzidas são adequadas, a fase de avaliação visa determinar, entre as ideias geradas, uma ideia que seja nova e adequada para ser implementada no contexto do problema (RIGOLIZZO; AMABILE, 2015). Ward (2004) indica que ideias de sucesso devem equilibrar novidade, para capturar a atenção do público, e familiaridade, visto que devem ser compreendidas, com o risco de serem rejeitadas caso sejam radicais demais.

Após a avaliação da ideia, a efetiva implementação está voltada ao conceito de inovação. Mas a etapa final de avaliação e implementação pode ser marcada pelo retorno às etapas anteriores, caso não sejam alcançados resultados satisfatórios. Ideias não selecionadas anteriormente podem ser usadas como base para uma nova geração ideias, ou mesmo o aprendizado obtido com o processo pode ser aplicado em uma redefinição do problema ou oportunidade (RIGOLIZZO; AMABILE, 2015).

Dane et al. (2011) revelam que o reconhecimento da importância da criatividade em diferentes contextos e domínios resultou no desenvolvimento de diversas técnicas de solução criativa de problemas, idealizadas para auxiliar o processo criativo. Conforme Eppler e Pfister (2012), as técnicas de criatividade atuam auxiliando os profissionais a serem mais criativos e facilitando a geração de ideias originais e viáveis, seja em equipe ou individualmente. 
De acordo com King e Schilicksupp (1999), as técnicas costumam ser aplicadas após o problema ser definido, os fatos serem estabelecidos e a necessidade de soluções alternativas ser verificada. Então, ferramentas para a geração de ideias são aplicadas em busca de soluções alternativas. A estimulação do pensamento criativo por estas técnicas ocorre por meio do incentivo ao pensamento flexível, mudança de perspectiva, associações alternativas, combinações de elementos não relacionados, entre outros mecanismos. Após a geração de alternativas, outras técnicas e ferramentas podem ser usadas para a seleção das melhores ideias.

Acompanhando o desenvolvimento de técnicas para solução criativa de problemas, verifica-se na literatura propostas de classificações das mesmas. Do ponto de vista teórico, as diferentes classificações buscam compreender os mecanismos envolvidos no funcionamento, o modo como as ideias são geradas e o grau de novidade das ideias produzidas, entre outras questões. Já a contribuição para o campo prático são diretrizes para auxiliar na seleção de técnicas para serem aplicadas, de acordo com o contexto que envolve o problema.

\subsection{Princípios das Técnicas de Criatividade}

Os princípios, critérios ou mecanismos que caracterizam o processo de geração de ideias é o aspecto das classificações de técnicas de criatividade usado como base teórica para este estudo. Assim, entre a variedade de classificações disponíveis, foram selecionadas as de Couger (1995 apud DANE et al., 2011), revisitada por Dane et al. (2011), e de McFadzean (2000). A classificação de Couger (1995 apud DANE et al., 2011) propõe duas abordagens possíveis para a geração de ideias - intuitiva e racional -, sendo esse o primeiro princípio adotado. Já a classificação de McFadzean (2000) tem como objetivo primário categorizar o nível de manutenção ou quebra de paradigma das técnicas. No entanto, esta classificação foi selecionada porque há dois princípios usados pela autora para classificar o funcionamento de técnicas que interessam a este estudo: o tipo de estímulo e o tipo de associação aplicados na técnica. Os princípios serão detalhados a seguir, junto a exemplos de técnicas criativas que os utilizam. 
Retomando o primeiro princípio, Couger (1995 apud DANE et al., 2011) classifica técnicas de criatividade de acordo com a abordagem proposta: intuitiva ou racional (Quadro 2). As técnicas que empregam abordagens racionais visam à produção criativa a partir de padrões de pensamento sistemático. Já as técnicas baseadas em abordagens intuitivas funcionam com associações cognitivas holísticas. Dane et al. (2011) complementam que o pensamento racional ocorre de modo sequencial ou linear. Para tanto, a resolução racional de problemas utiliza uma estrutura para produzir um padrão de pensamento lógico. No pensamento intuitivo, as etapas que precedem o resultado de um processo intuitivo não podem ser compreendidas racionalmente, visto que ocorrem em nível não consciente. Não há uma tentativa sistemática e analítica de resolução do problema (DANE et al., 2011).

Quadro 2 - Classificação de Técnicas de Criatividade Intuitivas e Racionais

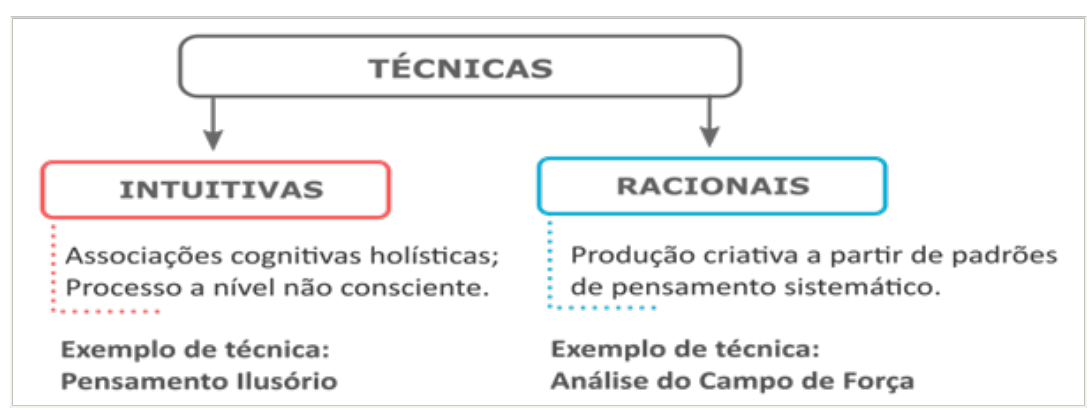

Fonte: Elaborado a partir de Couger (1995 apud DANE et al., 2011).

A técnica de criatividade Pensamento llusório exemplifica uma abordagem intuitiva de resolução de problemas. Após a definição do problema, os participantes devem ampliar a busca por soluções considerando que tudo é possível. Assim, são feitos desejos ou fantasias sobre uma solução ideal ao problema, que em seguida é convertida em uma solução prática, mais próxima da realidade. Estas, então, são 
avaliadas de modo analítico em busca da solução final. A aplicação de fantasia, proposta por esta técnica, facilita o abandono do pensamento racional, abrindo espaço para alternativas que não seriam pensadas comumente (COUGER; HIGGINS; MCINTYRE, 1993).

Um exemplo de técnica que aplica o pensamento analítico é a Análise do Campo de Força. O processo compreende a descrição de duas situações do problema em questão: uma ideal, e outra catastrófica. Após, identificam-se as forças que, no momento da aplicação da técnica, colaboram para o cenário ideal, bem como as forças que contribuem para o cenário catastrófico. Deste modo, a técnica trabalha com a geração de estímulos para o desenvolvimento de novas soluções de maneira sistemática, consistindo, portanto, em uma abordagem racional (COUGER; HIGGINS; MCINTYRE, 1993).

A segunda classificação utilizada neste estudo, de McFadzean (2000), é conhecida como Contínuo da Criatividade. As técnicas para solução criativa de problemas são categorizadas pela autora em preservação de paradigma, ampliação de paradigma ou quebra de paradigma (Quadro 3).

Quadro 3 - Classificação de Técnicas de Criatividade de McFadzean

\begin{tabular}{|c|c|c|}
\hline $\begin{array}{l}\text { PRESERVAÇÃO DE } \\
\text { PARADIGMA }\end{array}$ & $\begin{array}{l}\text { AMPLIAÇÃO DE } \\
\text { PARADIGMA }\end{array}$ & $\begin{array}{l}\text { QUEBRA DE } \\
\text { PARADIGMA }\end{array}$ \\
\hline $\begin{array}{c}\text { Entre os mecanismos de } \\
\text { funcionamento, utilizam a } \\
\text { associação livre de elementos e } \\
\text { estímulos relacionados ao problema }\end{array}$ & $\begin{array}{c}\text { Entre os mecanismos de } \\
\text { funcionamento, utilizam a associação } \\
\text { forçada de elementos e estímulos } \\
\text { não relacionados ao problema }\end{array}$ & $\begin{array}{c}\text { Entre os mecanismos de } \\
\text { funcionamento, utilizam a associação } \\
\text { forçada de elementos e estímulos } \\
\text { não relacionados ao problema }\end{array}$ \\
\hline Exemplo de técnica: & Exemplo de técnica: & Exemplo de técnica: \\
\hline Brainstorming & Estimulação de Objeto & Fantasia Guiada \\
\hline
\end{tabular}

Fonte: Elaborado a partir de McFadzean (2000). 
Como exemplo de preservação de paradigma, McFadzean (2000) propõe o Brainstorming, possivelmente a técnica de criatividade mais popular. Nela, os participantes comunicam suas ideias e o facilitador as anota em um quadro ou folha de papel, constituindo uma técnica que aplica expressão oral e escrita. O processo deve ser livre de julgamento, e os participantes são encorajados a produzir novas ideias a partir da combinação de ideias anteriores. O objetivo é gerar o maior número de ideias, visto que a quantidade eleva a probabilidade de serem produzidas boas ideias. Logo, esta técnica trabalha com a livre associação, e a estimulação para novas ideias decorre de informações relacionadas ao problema, resultando em estimulação criativa baixa.

A ampliação de paradigma é potencializada em técnicas que trabalham com associação forçada e estímulos não relacionados. A Estimulação de Objeto exemplifica esta categoria. A dinâmica da técnica prevê a descrição de objetos não relacionados ao problema pelos participantes. Estas descrições, que constituem expressão oral e escrita, servem como estímulos para gerar novas ideias quando relacionadas de volta ao problema. A ampliação de paradigma deriva desta aplicação de estímulos não relacionados e associação forçada (MCFADZEAN, 2000).

As técnicas de quebra de paradigma, do mesmo modo que as de ampliação, trabalham com o uso de estímulos não relacionados ao problema e com a associação forçada. A diferença é que nela o pensamento criativo é encorajado por meio de diferentes modos de expressão, como desenho, interpretação de papéis e pensamento fantasioso (MCFADZEAN, 2000). Por exemplo, na técnica Fantasia Guiada, os participantes devem descrever um cenário fantasioso, incluindo sentimentos, sons, cores e cheiros. Partindo do cenário, ideias são geradas e relacionadas novamente ao problema inicial. Este processo visa à criação de soluções originais e inovadoras (MCFADZEAN, 1998).

Este estudo não visa discutir o que configurariam possibilidades de manutenção, ampliação ou quebra de paradigmas na visualidade dos elementos da identidade gráfico-visual de marca. Logo, o recorte da teoria de McFazdean (2000) que interessa para a análise são os princípios relativos ao tipo de estímulos aplicados e tipo de associação, explicados acima no contexto das técnicas. 
As técnicas que empregam abordagens racionais visam à produção criativa a partir de padrões de pensamento sistemático.Já as técnicas baseadas em abordagens intuitivas funcionam com associações cognitivas holísticas.
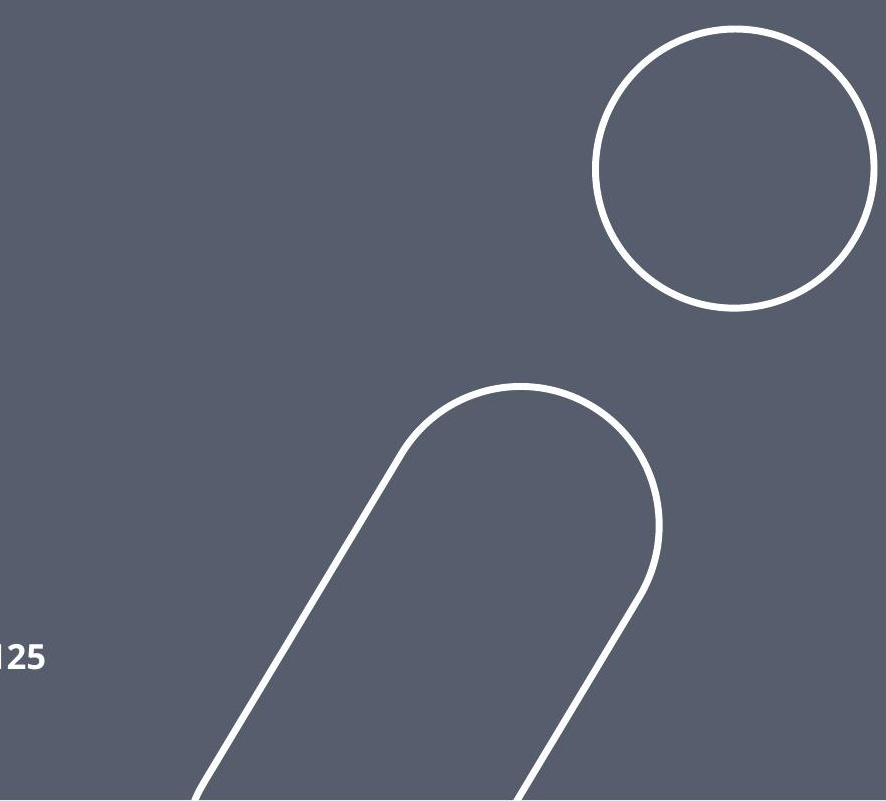
Assim, define-se como princípios a serem usados na análise do processo de criação de identidade gráfico-visual de marca: (1) o tipo de abordagem, que pode ser intuitiva ou racional, (2) o uso de estímulos relacionados ou não relacionados ao problema/situação, e (3) a associação livre ou forçada (Quadro 4)

Quadro 4 - Princípios de técnicas de criatividade

\begin{tabular}{|c|c|c|c|}
\hline \multicolumn{2}{|l|}{ PRINCÍPIO } & DESCRIÇÃO & REFERÊNCIA \\
\hline \multirow{2}{*}{ ABORDAGEM } & Intuitiva & Assistemática, associações cognitivas holisticas. & \multirow{2}{*}{$\begin{array}{l}\text { Couger (1995) e } \\
\text { Dane et al. (2011) }\end{array}$} \\
\hline & Racional & Modo sequencial ou linear, pensamento lógico. & \\
\hline \multirow{2}{*}{ ESTíMULOS } & $\begin{array}{l}\text { Relacionados } \\
\text { ao problema }\end{array}$ & $\begin{array}{l}\text { Elementos estimuladores pertencem ao } \\
\text { domínio do problema. }\end{array}$ & \multirow{2}{*}{ McFadzean (2000) } \\
\hline & $\begin{array}{l}\text { Não relacionados } \\
\text { ao problema }\end{array}$ & $\begin{array}{l}\text { Elementos estimuladores são buscados em } \\
\text { outros domínios. }\end{array}$ & \\
\hline \multirow{2}{*}{ ASSOCIAÇÃO } & Livre & Associações são feitas de modo natural. & \multirow{2}{*}{ McFadzean (2000) } \\
\hline & Forçada & $\begin{array}{l}\text { Associaçães entre elementos, estímulos ou } \\
\text { ideias são previstas pela técnica e obrigatórias. }\end{array}$ & \\
\hline
\end{tabular}

Fonte: Elaborado a partir de Couger (1995 apud Dane et al., 2011) e McFadzean (2000).

O primeiro princípio, tipo de abordagem que caracteriza a técnica criativa - intuitiva ou racional - trata da estruturação do processo. Mais especificamente, indica se o processo prevê, ou não, etapas a serem seguidas durante a criação. Isto repercute no modo como as ideias são geradas. Assim, temos uma técnica intuitiva quando o processo não é bem estruturado, privilegiando uma geração de ideias espontânea, natural, ao acaso. Nas técnicas racionais as etapas a serem executadas 
são bem definidas, assim, ao menos em parte, os processos e estímulos que resultaram nas ideias podem ser apontados, visto que se trata de ações realizadas de modo predominantemente consciente. Explicitar o caminho percorrido na geração de ideias de técnicas intuitivas é mais difícil, já que o processo intuitivo ocorre a nível não consciente.

A escolha do tipo de estímulos a serem aplicados - relacionados ou não ao problema - irá definir se a busca por soluções será, predominantemente, dentro ou fora do domínio em que se situa o problema. Quando são utilizados estímulos relacionados, é provável que as soluções se mantenham próximas do domínio do problema, resultando em ideias mais óbvias, mas também com maior probabilidade de serem adequadas. Já o uso de estímulos não relacionados amplia o alcance das ideias geradas para além do domínio do problema, e, como consequência, as ideias podem ser menos óbvias, mas nem sempre adequadas como solução.

A associação incentivada pela técnica, último princípio selecionado, irá influenciar o modo como os elementos ou estímulos envolvidos no processo serão tratados. A associação livre deixa a cargo do indivíduo ou grupo relacionar ou não os elementos identificados no desenvolvimento da técnica. A associação forçada prevê que elementos, estímulos ou ideias sejam obrigatoriamente associados. Da mesma forma que o anterior, este princípio pode influenciar na qualidade das ideias geradas, com a associação livre tendendo a combinações mais óbvias e adequadas, e associação forçada levando a ideias mais inovadoras, porém com maior risco de soluções ineficazes.

\subsection{A etapa Criativa dos Projetos de Identidade Gráfico-visual de Marca}

Há diversas metodologias de projeto de Design disponíveis na literatura, sejam voltadas para projetos de Design em geral, ou próprias para áreas de atuação, como Design de Produtos ou Design Gráfico. Inclusive, o desenvolvimento de identidade gráfico-visual de marca, como uma subárea do Design Gráfico, também dispõe de metodologias ou diretrizes específicas (e.g. PEÓN, 2001; STRUNCK, 2012; WHEELER, 2012). 
A partir de uma análise de diferentes metodologias de Design, Cameira (2013) concluiu que as voltadas ao desenvolvimento de identidade gráfico-visual de marca não diferem em essência daquelas usadas para a atividade de Design em geral. Também, a autora verificou que a maior parte das metodologias, tanto gerais como para identidade de marca, são constituídas por uma etapa inicial de análise da problemática, seguida de uma etapa reservada ao desenvolvimento da solução, e, por fim, de uma etapa onde a solução é implementada.

A metodologia de construção de sistemas de identidade visual proposta por Peón (2001) corrobora o afirmado por Cameira (2013), sendo composta por três fases principais: (1) Problematização; (2) Concepção; e (3) Especificação. A fase inicial de Problematização visa o diagnóstico da situação de projeto. Na fase de Concepção, são geradas alternativas e selecionada a solução gráfica a ser adotada, e a fase final de Especificação consta na viabilização da implementação do sistema de identidade visual.

Quadro 5 - Resumo das etapas principais dos projetos de identidade gráfico-visual

\begin{tabular}{|c|c|c|}
\hline 1 & 2 & 3 \\
\hline EXPLORATÓRIA & CRIATIVA & EXECUTIVA \\
\hline Estudo do contexto & $\begin{array}{l}\text { Geração e seleção } \\
\text { de alternativas }\end{array}$ & $\begin{array}{l}\text { Implementação } \\
\text { da solução }\end{array}$ \\
\hline
\end{tabular}

Fonte: Elaboração própria.

Em síntese, verifica-se que embora apresentem variações nas técnicas e ferramentas aplicadas, as diversas metodologias de Design são estruturadas em três etapas principais, que serão denominadas aqui de (1) exploratória, (2) 
criativa e (3) executiva (Quadro 5). A etapa exploratória é caracterizada pelo estudo do contexto do projeto, e não prevê produção material. As etapas criativa e executiva são marcadas pelo desenvolvimento de soluções para o projeto, a partir das informações coletadas na etapa exploratória. Na parte criativa são geradas alternativas e selecionada a solução, e na parte executiva a solução é implementada.

O recorte deste estudo é a geração de alternativas de solução da etapa criativa. O processo de criação dos elementos da identidade gráfico-visual de marca é guiado pelos conceitos da identidade de marca, identificados na etapa exploratória anterior. A identidade de marca costuma ser sintetizada por cerca de quatro ou cinco conceitos. Antes do início da produção de alternativas, é comum a construção de painéis imagéticos, inclusive os painéis semânticos (mood boards), como ferramentas prévias ao desenho de alternativas.

Painel semântico ou mood board é uma coleção de imagens selecionadas para comunicar um humor ou atmosfera durante o projeto de Design (MCDONAGH; DENTON, 2005). Nos projetos de identidade de marca, os painéis semânticos ou imagéticos podem ser compostos por imagens, cores, formas, texturas e tipografias, entre outros elementos, que são considerados coerentes com os conceitos da identidade de marca. A quantidade e estilo dos painéis variam de acordo com cada projeto. Podem ser construídos painéis para cada um dos conceitos, ou um painel geral para sintetizar a identidade da marca, ou ainda painéis específicos com referências de cores, tipografias, formas ou figuras.

Apesar de comuns, os painéis não são a única ferramenta prévia ao desenho de projetos de identidade gráfico-visual de marca. Também pode ser utilizada, por exemplo, a pesquisa por assinaturas visuais de marcas similares, pesquisa de assinaturas visuais diversas que expressem conceitos semelhantes à identidade da marca em questão, ou ainda a busca de imagens e outros estímulos visuais sem a pretensão de construir um painel. Em resumo, a etapa prévia ao desenho busca reunir estímulos visuais coerentes com os conceitos requeridos pelo projeto, servindo como inspiração ou referência para a geração de alternativas. 
Há ainda ferramentas projetuais de orientação, que buscam pré-definir diretrizes para a solução, indicando cores, formas e tipografias a serem trabalhadas. Um exemplo é a Matriz de Recomendações, proposta por Fascioni (2006). As recomendações objetivam traçar um alinhamento entre a identidade corporativa e a identidade visual, e funcionam através do detalhamento dos critérios: forma, cores, tipografia e elementos. Segundo Fascioni (2006), a matriz auxilia o designer a manter coerência entre os conceitos da marca e sua expressão gráfica, porém não deve ser detalhada em excesso, já que isto significaria uma limitação da capacidade criativa.

Em geral, o processo de geração de alternativas, como indicado na literatura e utilizado na prática, consta de uma fase inicial de criação de esboços de soluções, seguido de aprimoramento das ideias mais interessantes geradas (STRUNCK, 2012; WHEELER, 2012). Este processo pode ser repetido caso as ideias dos esboços iniciais não levem a alternativas satisfatórias.

Os esboços iniciais costumam ser voltados à assinatura visual, já que esta é considerada o símbolo-síntese do sistema de identidade visual (ZWIRTES; NUNES; DE Souza, 2014), sendo os demais elementos do sistema comumente derivados dela (PEÓN, 2001). Ideias iniciais de formas, logotipos ou símbolos são desenhadas à mão ou em softwares gráficos. Peón (2001) ressalta que quanto mais alternativas forem geradas, melhor para o processo. Wheeler (2012) afirma que podem chegar a ser examinadas centenas de ideias antes da definição da solução a ser adotada.

Após a criação de esboços iniciais, estes são avaliados, e as alternativas mais promissoras são selecionadas para aperfeiçoamento. É comum que ideias avaliadas positivamente deem origem a diversas alternativas baseadas em seus atributos. Wheeler (2012) destaca também que as ideias iniciais podem dar início a novas abordagens. Assim, não é possível prever quantas alternativas serão geradas, nem quantas etapas de aperfeiçoamento serão necessárias até o desenvolvimento da solução final.

Após a geração ideias, e o aperfeiçoamento das melhores alternativas, cerca de duas ou três destas são pré-selecionadas para serem finalizadas e apresentadas 
ao cliente, ou ainda avaliadas através de pesquisas qualitativas ou quantitativas para a seleção da solução final (PEÓN, 2001). Neste momento, todas as alternativas pré-selecionadas costumam ser coerentes com os conceitos da identidade de marca, sendo a decisão final reservada a impressões subjetivas dos responsáveis pela escolha final. A seleção da solução marca o fim da etapa criativa. Então, na etapa executiva são feitos os detalhamentos técnicos da solução, preparando-a para ser aplicada.

\section{DISCUSSÃO}

É evidente que cada projeto de Design de identidade gráfico-visual de marca apresenta particularidades. No entanto, a seção acima buscou relatar, de modo geral, os processos típicos que permeiam a geração de alternativas da parte criativa, proporcionando uma base para que esta fase seja analisada a partir dos princípios de técnicas de criatividade apresentados anteriormente.

Como apontam Garfield et al. (2001), a geração de ideias pode ser uma atividade individual ou em equipe. No segundo caso, esta atividade é um processo cognitivo e social. O presente estudo não pretende abordar as interações de um processo criativo em equipe, focando apenas nos princípios que são usados para gerar ideias. Assim, considera-se aqui um processo individual.

Acerca do primeiro princípio, o tipo de abordagem aplicada no processo criativo, a intuição prevalece sobre a racionalidade. Isto se justifica pois, comumente, a geração de alternativas para os símbolos da identidade gráfico-visual não é feita a partir de regras ou de uma estrutura rígida. Cada esboço produzido decorre de uma impressão, ideia ou referência, e o modo como o desenho irá evoluir é livre. Por exemplo, as formas, cores e texturas são testadas em diferentes composições, e a partir dos esboços iniciais, novas ideias surgem e dão origem a outras linhas criativas. 
O caráter intuitivo da fase de geração de ideias é verificado na própria dificuldade de explicar o processo a partir de uma estrutura rígida, como foi verificado na seção anterior. Em uma abordagem racional, o pensamento segue uma estrutura sequencial ou linear (DANE et al., 2011), com estímulos aplicados de modo sistemático para gerar novas soluções (COUGER; HIGGINS; MCINTYRE, 1993). Assim, apesar da existência de algumas abordagens sistemáticas para determinadas ações do processo criativo, o uso da intuição predomina na criação dos elementos de identidade gráfico-visual.

Sobre o segundo princípio a ser discutido, o tipo de estímulos utilizados no processo, a geração de alternativas é caracterizada por empregar estímulos relacionados ao problema. Estes incluem elementos selecionados previamente ao desenho de alternativas, configurando os painéis imagéticos ou semânticos e demais referências visuais do projeto. Ferramentas similares à Matriz de Recomendações (FASCIONI, 2006) também constituem estímulos relacionados.

Durante a pesquisa por referências ou inspiração, o designer observa os mais diversos tipos de estímulos visuais, configurando possiblidades ilimitadas para serem avaliadas. Após este momento inicial de divergência, os conceitos da identidade da marca atuam como orientação para a seleção de determinadas cores, texturas, formas, figuras, tipografias e outros elementos. Logo, os estímulos selecionados como inspiração ou referência são aqueles que atenderam aos critérios da problemática do projeto.

Sem dúvida os estímulos apresentam variações, visto que não são limitados a uma determinada cor, forma e estilo tipográfico, por exemplo. Inclusive, o designer não necessariamente se limita a criar esboços a partir dos estímulos préselecionados, podendo aplicar elementos que surgem de associações feitas durante o desenho. Mas a classificação de McFadzean (2000) especifica que estímulos não relacionados ao problema derivam da busca deliberada por elementos ou objetos fora do contexto da problemática em questão, enquanto mesmo novos estímulos, originados de associações durante a criação de esboços, surgem dentro da perspectiva que está sendo trabalhada. 
O caráter intuitivo da fase de geração de ideias é verificado na própria dificuldade de explicar o processo a partir de uma estrutura rígida, como foi verificado na seção anterior. Em uma abordagem racional, o pensamento segue uma estrutura sequencial ou linear (DANE et al., 2011), com estímulos aplicados de modo sistemático para gerar novas soluções (COUGER; HIG GINS; MCINTYRE, 1993). Assim, apesar da existência de algumas abordagens sistemáticas para determinadas ações do processo criativo, o uso da intuição predomina na criação dos elementos de identidade gráfico-visual. 
O terceiro critério se refere ao tipo de associação feita durante a técnica criativa, que segundo McFadzean (2000) pode ser livre ou forçada. Na geração de alternativas em estudo, a associação é predominantemente livre. Uma associação forçada decorre da aplicação de certos estímulos, previamente selecionados, na solução do problema de modo obrigatório. Por exemplo, no presente caso, consiste em trabalhar na criação de esboços com determinadas formas, cores, e demais elementos pré-definidos.

Quadro 6 - Resumo dos princípios da geração de alternativas em Design de identidade gráfico-visual

\begin{tabular}{|l|l|l|}
\hline \multicolumn{2}{|l|}{ PRINCÍPIOS } & JUSTIFICATIVA \\
\hline ABORDAGEM & Intuitiva & $\begin{array}{l}\text { Em geral, não existem regras ou estrutura rígida para a geração de ideias. } \\
\text { A criação resulta de impressões, inspirações ou referências e evolui de } \\
\text { modo livre. Não é possível prever quantas etapas de esboço, seleção e } \\
\text { finalização de alternativas serão percorridas. }\end{array}$ \\
\hline ESTÍMULOS & $\begin{array}{l}\text { Relacionados } \\
\text { ao problema }\end{array}$ & $\begin{array}{l}\text { Os elementos estimuladores são selecionados pelo designer por serem } \\
\text { adequados aos conceitos da identidade da marca. A princípio, a busca ou } \\
\text { associação espontânea de cores, formas e tipografias é mantida dentro do } \\
\text { contexto do problema, mantendo coerência com os conceitos da marca. }\end{array}$ \\
\hline ASSOCIAÇÃO & Livre & $\begin{array}{l}\text { Observa-se uma dinâmica livre no processo. Os elementos são testados e } \\
\text { combinados de acordo com a sensibilidade do designer. }\end{array}$ \\
\hline
\end{tabular}

Fonte: Elaboração própria, princípios retirados de Couger

(1995 apud Dane et al., 2011) e McFadzean (2000).

Sem desconsiderar a existência de ferramentas que sistematizam a aplicação de determinados elementos, o que é geralmente observado no desenho de esboços é uma dinâmica livre, na qual o designer aplica os elementos de acordo com a sensibilidade, sem necessariamente forçar combinações. Elementos de diferentes esboços podem ser mesclados, cores e texturas trocadas, mas trata-se 
de decisões predominantemente intuitivas, e não de ações previstas racionalmente pela técnica de criação.

Percebe-se, assim, que os três princípios predominantemente aplicados na geração de alternativas da parte criativa de Design de identidade gráfico-visual - intuição, estímulos relacionados ao problema e livre associação (Quadro 6) configuram uma abordagem onde a aplicação de cada princípio é coerente com os demais. Em especial, a ausência de estruturação, que configura o princípio intuitivo, condiz com a livre associação de estímulos. Em resumo, é um processo que se apoia principalmente na experiência e sensibilidade estética do designer para gerir o percurso criativo e chegar a ideias originais.

Considerando a abordagem intuitiva como promotora de associações livres, por outro lado, uma abordagem criativa predominantemente racional pode ser alcançada através da associação forçada. Neste caso, a técnica criativa deve prever uma sequência de eventos em que determinados elementos visuais sejam usados obrigatoriamente nos esboços. No entanto, é importante destacar que uma estruturação racional de passos a serem aplicados na geração de alternativas nunca irá abranger todas as ações e decisões da criação. Sempre haverá necessidade de espontaneidade, improvisação ou experimentação em determinados momentos, que caracterizam o processo intuitivo.

Os elementos visuais aplicados em uma abordagem predominantemente racional podem ser estímulos relacionados ou não com os conceitos da identidade de marca. Uma aplicação sistemática de elementos selecionados por uma ferramenta de orientação, como a Matriz de Recomendações de Fascioni (2006), na qual os elementos foram pré-selecionados para expressar os conceitos do projeto, exemplifica um caso de aplicação de estímulos relacionados à problemática. Elementos não relacionados devem ser deliberadamente buscados fora da problemática do projeto.

Entre as demais possibilidades de combinação entre os três princípios analisados, é interessante discutir uma possível abordagem predominantemente racional na qual a técnica prevê a aplicação obrigatória de estímulos não 
relacionados ao problema. A criação de esboços com elementos que, a priicínín, são avaliados como não relacionados com os conceitos da identidade de marca, é normalmente evitada. A inserção sistemática e obrigatória de elementos não relacionados poderia tirar o foco da criação, resultando em esboços e alternativas que não representam os conceitos da marca, e podendo cair na produção de ideias irrelevantes alertada por Kozbelt, Beghetto e Runco (2010).

A seleção de estímulos como referência ou inspiração para a criação decorre do fato de que certos elementos visuais, sem rigor, são tradicionalmente relacionados a determinados sentidos (PERASSI, 2015). Inclusive, são estas relações que tornam possível a elaboração de ferramentas projetuais de orientação da criação. Mas é difícil prever exatamente os sentidos capazes de serem expressos pelas mais diversas combinações visuais. Portanto, um elemento visual considerado, em primeiro momento, incoerente com a identidade da marca, pode ser trabalhado de modo a gerar uma ideia satisfatória e inovadora. Logo, acredita-se que o uso de técnica predominantemente racional de aplicação forçada de elementos não relacionados tem potencial para gerar soluções adequadas.

Nesta linha de raciocínio, podemos retomar a teoria do Contínuo da Criatividade de McFadzean (2000). A autora caracteriza a ampliação ou quebra de paradigma ao uso, entre outros princípios, de estímulos não associados e relações forçadas. Deixando a noção de paradigma de lado, e substituindo-a por uma indicação de grau de novidade da ideia, definida por Garfield et al. (2001) como a sua raridade ou singularidade, é sugerido aqui que esta combinação de princípios - racionalidade, estímulos não relacionados e associação forçada - tem a potencialidade de originar ideias mais originais e inovadoras. Mas, este caso demandaria um cuidado especial na etapa de convergência, onde é feita a seleção das ideias produzidas, priorizando apenas as soluções coerentes com a identidade de marca. 


\section{CONSIDERAÇÕES FINAIS}

Este trabalho apresentou um estudo de caso sobre o uso de resultados de avaliação formativa durante o processo de design para a melhoria da solução digital sendo concebida. Os 52 problemas identificados pela avaliação heurística, método de avaliação de comunicabilidade de teste de usabilidade foram estratificados pelo local afetado na interface com usuário do protótipo avaliado. Os problemas identificados foram justapostos às respectivas modificações para melhoria da solução de IHC. Em geral, um problema encaminhou uma modificação na solução. Quando se tratavam dos mesmos problemas encontrados por métodos diferentes, ou ocorriam na mesma parte da interface (widget) ou eram relacionados ao mesmo objetivo, o designer considerou vários problemas em conjunto para repensar sua solução. Nestes casos, ele acabou deixando de considerar a necessidade de rever alguns comportamentos indesejáveis na sua solução original, pelo menos de forma explícita nos seus comentários sob a solução revisada.

Apesar deste relato de estudo de caso ser um importante indício de como a avaliação formativa pode contribuir com o processo de design, o assunto está longe de ser esgotado. Trabalhos futuros deveriam realizar estudos semelhantes com outros designers, outros sistemas computacionais e outros contextos. A reflexão do designer durante a revisão da solução sendo concebida poderia ser analisada em mais detalhes. O que influencia as decisões do designer nesta etapa do processo? Como apoiar o designer adequadamente? Como evitar que coisas importantes passem despercebidas ou acabem sendo ignoradas diante da quantidade e complexidade de informações analisadas pelo designer? Futuras investigações sobre essas questões deveriam envolver: (1) uma melhor compreensão dos problemas encontrados em uma avaliação do uso de uma solução digital (sistema computacional interativo); (2) análise de impacto das condições em que a avaliação foi realizada, tais como cansaço e stress dos avaliadores, pressões sociais e demais fatores ambientais; (3) análise de custo/benefício de outros avaliadores revisarem 
os resultados da avaliação; (4) desenvolvimento de métodos e ferramentas (inclusive com suporte computacional de softwares e hardwares) para apoiar a análise do resultados de avaliação e a revisão da solução sendo concebida; e (5) analisar como as representações da solução original, dos resultados da avaliação e da solução revisada influenciam o processo de design na melhoria da solução sendo concebida.

\section{Apoio}

O presente trabalho foi realizado com apoio da Coordenação de Aperfeiçoamento de Pessoal de Nível Superior - Brasil (CAPES) - Código de Financiamento 001. 
Os princípios do processo criativo... marca

SCHMIEGELOW, S. S.; SOUSA, R. P. L. de

\section{REFERÊNCIAS}

1. ALENCAR, Eunice M. L. Soriano. A gerência da criatividade. São Paulo: Makron Books, 2005.

2. BÜRDEK, Bernhard E. História, teoria e prática do design de produtos. São Paulo: Edgard Blücher, 2006.

3. CAMEIRA, Sandra Ribeiro. O branding e a metodologia de sistemas de identidade visual. Dissertação de mestrado (Design e Arquitetura)Faculdade de Arquitetura e Urbanismo - USP. São Paulo, 2013

4. COUGER, J. Daniel; HIGGINS, Lexis F.; MCINTYRE, Scott C. (Un)structured creativity in information systems organizations. MIS Quarterly, Minneapolis, v. 17, n. 4, p. 375-397, 1993. Disponível em: https://search.proquest.com/ docview/218112154?pq-origsite=gscholar. Acesso em: 3 maio 2018.

5. DANE, Erick; BAER, Markus; PRATT, Michael G.; OLDHAM, Greg R. Rational versus intuitive problem solving: how thinking "of the beaten path" can stimulate creativity. Psychology of Aesthetics, Creativity and the Arts, Washington, D C, v. 5, n. 1, p. 3-12, 2011. Disponível em: 10.1037/a0017698. Acesso em: 3 maio 2018.

6. EPPLER, Martin J.; PFISTER, Roland A. Paths to success: a sketch-based creativity technique for individuals and teams. In: INTERNATIONAL CONFERENCE ON INFORMATION VISUALIZATION, 16., 2012, Montpellier, France. Proceedings [...]. Montpellier: IEEE, 2012. p. 337-242. Disponível em: 10.1109/IV.2012.63. Acesso em: 1 maio 2018. 
Projética, Londrina, v. 12, n. 1, p. 114-142, março 2021

7. FAYGA Ostrower: sensibilidade e criação. Rio de Janeiro, RJ, 2010.

8. FASCIONI, Lígia Cristina. Uma proposta para o alinhamento estruturado entre a identidade corporative e a identidade visual. In: CONGRESSO BRASILEIRO DE PESQUISA E DESENVOLVIMENTO EM DESIGN, 7., Curitiba, PR, 2006. Anais eletrônicos [...]. Curitiba: UNICENP, 2006. Disponível em: http:// www.ligiafascioni.com.br/wp-content/uploads/2010/08/PD2006_ligia.pdf. Acesso em: 5 maio 2018.

9. GARFIELD, Monica J.; TAYLOR, Nolan J.; DENNIS, Allan R.; SATZINGER, Jonh W. Research report: modifying paradigms: individual differences, creativity techniques, and exposure to ideias in group ideia generation. Information Systems Research, Minnesota, Minneapolis, v. 12, n. 3, p. 322333, 2001. Disponível em: https://search.proquest.com/docview/208162742/ fulltextPDF/43FF559F7C1745BEPQ/1?accountid=26642. Acesso em: 1 maio 2018.

10. HENNESSEY, Beth A.; AMABILE, Teresa M. Creativity. Annual Review of Psychology, Palo Alto, CA, v. 61, p. 569-598, 2010. Disponível em: 10.1146/ annurev.psych.093008.100416. Acesso em: 29 mar. 2018.

11. KAPFERER, Jean-Noel. The new strategic brand management: creating and sustaining brand equity long term. London: Kogan Page Publishers, 2008.

12. KING, Bob; SCHLICKSUPP, Helmut. Criatividade: uma vantagem competitiva. Rio de Janeiro: Qualitymark, 1999.

13. KOZBELT, Aaron; BEghetTo, Ronald A.; RUNCO, Mark A. Theories of creativity. In: KAUFMAN, James C.; STERNBERG, Robert J. (ed.). The Cambridge handbook of creativity. New York: Cambridge University Press, 2010. 
Os princípios do processo criativo... marca

SCHMIEGELOW, S. S.; SOUSA, R. P. L. de

14. LÖBACH, Bernd. Design industrial: bases para a configuração dos produtos industriais. São Paulo: Blücher, 2001.

15. MCDONAGH, Deana; DENTON, Howard. Exploring the degree to which individual students share a common perception of specific mood boards: observations relating to teaching, learning and team-based design. Design Studies, Amsterdã, v. 26, n. 1, p. 35-53, 2005. Disponível em: https://doi. org/10.1016/j.destud.2004.05.008. Acesso em: 4 maio 2018.

16. MCFADZEAN, Elspeth. Techniques to enhance creative thinking. Team Performance Management: an International Journal, Bradford, UK, v. 6, n. 3-4, p. 62-72, 2000. Disponível em: 10.1108/13527590010731989. Acesso em: 1 maio 2018.

17. MCFADZEAN, Elspeth. The creativity continuum: towards a classification of creative problem solving techniques. Creativity and Innovation Management, Aalborg, Dinamarca, v. 7, n. 3, p. 131-139, 1998.

18. PEÓN, Maria Luísa. Sistemas de identidade visual. Rio de Janeiro: 2AB, 2001.

19. PERASSI, Richard. Do ponto ao pixel: sintaxe gráfica no videodigital. Florianópolis: CCE/UFSC, 2015.

20. RIGOLIZZO, Michele; AMABILE, Teresa. Entrepreneurial creativity: the role of learning processes and work environment supports. In: SHALLEY, Christina E.; HITT, Michel A.; ZHOU, Jing. (ed.). Oxford library of psychology. New York: Oxford University Press, 2015.

21. STRUNCK, Gilberto. Como criar identidades visuais para marcas de sucesso. Rio de Janeiro: Rio Books, 2012. 
Projética, Londrina, v. 12, n. 1, p. 114-142, março 2021

22. VALENTIM, Marta L. P. Métodos qualitativos de pesquisa em ciência da informação. São Paulo: Ed. Polis, 2005.

23. VANZIN, Tarcísio; ULBRICHT, Vania Ribas. Criatividade, mitologia e hemisférios cerebrais. In: ULBRICHT, Vania Ribas; VANZIN, Tarcísio; ZANDOMENEGHI, Lúcia A. de O. (org.). Criatividade e conhecimento. Florianópolis: Pandion, 2010. p. 29-49.

24. WARD, Thomas B. Cognition, creativity and entrepreneurship. Journal of Business Venturing, Amsterdã, v. 19, n. 2, p. 173-188, 2004. Disponível em: https://doi.org/10.1016/S0883-9026(03)00005-3. Acesso em: 1 maio 2018.

25. WHEELER, Alina. Design de identidade de marca. 3. ed. Porto Alegre: Bookman, 2012.

26. ZWIRTES, A. M.; NUNES, C. C.; DE SOUSA, R. P. L. Mídia, identidade e ambiente na comunicação da marca "FARM". Lumina, v. 6, n. 2, 31 jul. 2014. 